cannulation in children with a eutectic mixture of lidocaine and prilocaine (EMLA cream): comparison with placebo cream and no local premedication. Acta Anaesthesiol Scand 1987;31 735-9.

8 Hallen B, Olsson GL, Uppfeldt A. Pain-free venepuncture. Effect of timing of application of local anaesthetic cream. Anaesthesia 1984;39:969-72.

9 Hopkins CS, Buckley CJ, Bush GH. Pain-free injection in infants. Use of a lignocaine-prilocaine cream to prevent pain at intravenous induction of general anaesthesia in 1-5 year-old children. Anaesthesia 1988;43:198-201.

10 Juhlin L, Rollman O. Vascular effects of a local anaesthetic mixture in atopic dermatitis. Acta Derm Venereol (Stockh) 1984;64:439-40.

11 Evers H, Von Dardel O, Juhlin L, Ohlsen L, Vinnars E. Dermal effects of compositions based on the eutectic mixture of lignocaine and prilocaine (EMLA). Studies in volunteers. Br f Anaesth 1985;57:1005.
12 Juhlin L, Everts H, Broberg F. A lidocaine-prilocaine cream for superficial skin surgery and painful lesions. Acta Derm Venereol (Stockh) 1980;60:544-6.

13 Jakobson B, Nilsson A. Methemoglobinemia associated with a prilocaine-lignocaine cream and trimetoprim-sulphamethoxazole. A case report. Acta Aneesthesiol Scand 1985;29:453-5.

14 Engberg G, Danielson K, Henneberg S, Nilsson A. Plasma concentrations of prilocaine and lidocaine and methaemoglobin formation in infants after epicutaneous application of a $5 \%$
lond lidocaine-prilocaine cream (EMLA). Acta Anaesthesiol Scand 1987;31:624-8.

15 Young AC, Shorthall A, Haynes W, Young G. Lignocaine-prilocaine cream for lumbar puncture. Lancet 1987; ii: 1533.

16 Price HV. Lignocaine-prilocaine cream for lumbar puncture in children. Lancet 1988;i:1174.

17 Ohlsen L, Englesson S, Evers H. An anaesthetic lidocaine/prilocaine cream (EMLA) for

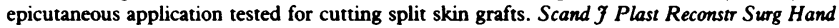
Surg 1985;19:201-9.

\title{
Veterinary medicines in animal foods
}

\author{
Reassuring findings but surveillance should go on
}

Consumers' organisations have become anxious about intentional and unintentional food additives, among which may be residues of drugs given to animals reared for food. There is less concern about antimicrobial drugs given occasionally to an animal with an acute infection than about the use of anabolic hormones to increase the efficiency of meat production. If the hormones carry over into the meat or milk in adequate amounts they might cause effects or chronic toxicity.

Veterinary surgeons now have less freedom in prescribing for farm animals than doctors have for humans. Many drugs are banned, and others can be given only to some animals by specified routes, with a defined withdrawal period before slaughter or taking milk or eggs for consumption. Farmers have to follow the written veterinary instructions or in some cases they may be liable to prosecution. They are also having to follow not only the code of practice of the Ministry of Agriculture, Fisheries, and Food but, increasingly, the directives of the European Community. Thus chloramphenicol is licensed for only restricted veterinary uses. Diethylstilboestrol and the related stilbene oestrogens that had been used as growth promoters were prohibited in Britain in 1982 in harmony with the European Community. Diethylstilboestrol is a known carcinogen, orally active and persistent. The European Community went further in 1986, banning the use of all hormone growth promoters, against the advice of its own scientific group, which had evidence that properly used natural hormones such as testosterone or progesterone produce unimportant residues in meat and are no risk to health. ${ }^{1}$ The United Kingdom has had to follow suit.

Nevertheless, making regulations is useless unless they can be enforced. Specialised analysts in Britain and elsewhere have developed specific and sensitive methods for detecting residues of veterinary medicines in food. Typically these methods are radioimmunoassay or high performance liquid chromatography. Controlled animal trials have to be done to see which $\operatorname{organ}(\mathrm{s})$ concentrate(s) the residues, which metabolites are formed, and how long the drug and its metabolites persist after the usual dosage. Choices have to be made between random sampling of the main abattoirs in proportion to their throughput and sampling tissues from special subgroups of animals that seem particularly likely to have been given the drugs. Choices have also to be made between home produced and imported meat.

The working party on veterinary residues in animal products of the Ministry of Agriculture, Fisheries, and Food.has reported the results of analyses carried out between 1979 and 1985 on animal products. These looked for residues of the three major groups of agents used in veterinary medicinesanabolic, anthelmintic, and antimicrobial compounds. ${ }^{2}$ The proportion of samples containing diethylstilboestrol was $8 \%$ in 1981, the year before it was banned; it has since fallen to $0.3 \%$. In six cases illegal use was suspected (in calves or pigs), and in two of these the persons responsible were prosecuted and fined. Minute amounts of a different and apparently safer anabolic agent, zeranol, were found in some beef samples during 1983-4. This drug was prohibited in 1986 but surveillance will be continued as a precaution. In 1981 samples of fat from male calves and samples of plasma from female calves were analysed for progesterone and testosterone, respectively: the concentrations of both were inside the normal range in all samples.

The anthelmintic compounds looked for were levamisole and five benzimidazole compounds (such as thiabendazole and mebendazole). No residues were found in either liver or meat - a reassuring result because levamisole may cause agranulocytosis in man. Samples of milk will now be analysed in a similar way.

A non-specific bacteriological test for antimicrobial activity gave positive results in about $1 \%$ of animals between 1980 and 1983, particularly in kidneys from cattle and pigs. Sulphadimidine was detected chemically in a fifth of the pigs' kidneys, half of which had concentrations above the maximum acceptable value of $0.1 \mathrm{mg} / \mathrm{kg}$. The Ministry of Agriculture, Fisheries, and Food has informed pig farmers of the results and of the need to observe withdrawal periods. No chloramphenicol or furazolidone was detected in kidneys from quadrupeds or farmed trout, respectively. Oxytetracycline was found in some samples of farmed trout at concentrations averaging $0.2 \mathrm{mg} / \mathrm{kg}$. Such concentrations are unlikely to have any toxicological consequences, though there is still a possibility of inducing bacterial resistance to antibiotics. The working party is now developing similar chemical methods for residues of aminoglycosides, penicillins, and cephalosporins.

These findings should reassure the public about this aspect of the safety of foodstuffs derived from animals. The British system of surveillance entails hard work for several ministerial committees, abattoirs throughout the country, seven analytical laboratories, the veterinary profession, and farmers' organisations. All this costs money, but it is clearly important that surveillance should carry on.

A STEWART TRUSWELL Boden Professor of Human Nutrition, University of Sydney, New South Wales 2006, Australia

1 Gormley TR, Downey G, O'Beirne D. Food, health and the consumer. London: Elsevier Applied Science, 1987. (Report from the forecasting and assessment in the field of science and technology (FAST) programme of the Commission of the European Communities.)

2 Ministry of Agriculture, Fisheries, and Food. Anabolic, anthelmintic and antimicrobial agents. London: HMSO, 1987. (22nd report of the Steering Group on Food Surveillance. The Working Party on Veterinary Residues in Animal Products.) 